\begin{tabular}{|c|c|c|}
\hline \multirow{3}{*}{$\begin{array}{l}\text { ITC 2/48 } \\
\text { Journal of Information Technology } \\
\text { and Control } \\
\text { Vol. } 48 / \text { No. } 2 / 2019 \\
\text { pp. 250-267 } \\
\text { DOI 10.5755/j01.itc.48.2.21667 }\end{array}$} & \multicolumn{2}{|c|}{$\begin{array}{l}\text { A Comparison of the Control Schemes of Human } \\
\text { Response to a Dynamic Virtual 3D Face }\end{array}$} \\
\hline & Received 2018/09/18 & Accepted after revision 2019/04/30 \\
\hline & \multicolumn{2}{|c|}{ Cross 5 http://dx.doi.org/10.5755/j01.itc.48.2.21667 } \\
\hline
\end{tabular}

\title{
A Comparison of the Control Schemes of Human Response to a Dynamic Virtual 3D Face
}

\section{Kaminskas, E. Ščiglinskas}

Faculty of Informatics; Vytautas Magnus University; Vileikos Str. 8, LT-Kaunas, Lithuania; phone: +37064632139; e-mails: vytautas.kaminskas@vdu.lt, edgaras.sciglinskas@vdu.lt

Corresponding author: edgaras.sciglinskas@vdu.lt

This paper introduces the application of predictor-based control principles for the control of human response to a virtual 3D face. A dynamic woman 3D face is observed in virtual reality. We use changing distance-between-eyes in a 3D face as a stimulus - control signal. Human responses to the stimulus are observed using EEG-based excitement signals - output signal. The technique of dynamic systems identification which ensures stability and possible higher gain of the model for building a predictive input-output model of control plant is applied. Three predictor-based control schemes with a minimum variance or a generalized minimum variance control quality and constrained control signal magnitude and change rate are developed. High prediction accuracies and control quality are demonstrated by modelling results.

KEYWORDS: Virtual 3D Face, Human Excitement, Predictive Input-Output Model, Minimum variance and Generalized Minimum Variance Control with Constraints.

\section{Introduction}

Emotions are very important to human experience because they play an important role in human daily lives - communication, rational decision making and learning [35], [38]. New advanced technologies and sensors allowed to create devices, which could be used not only in the laboratories and medical institutions [11], [33]. These devices allow to obtain EEG signals and extract emotions in real time and could be used in normal live situations - listening to the music [30], playing games [13], [47], watching movies [36], stabilizing concentration of the critical systems operators - making communication more intuitive with human-computer interfaces [43].

This research field because of its potential and possible various applications is growing rapidly. Emotions as reaction to the various stimuli analysis [3], model- 
ling [45], recognition [44] and investigation of a feedback systems [31] are expanding. Individual emotional responses vary greatly and a single emotional model cannot be developed for a group of people, so for this purpose a control mechanism is necessary [10].

The most popular way to observe a human emotion in real time is to monitor EEG-based signals as response to stimuli (visual, audio, etc.) [11], [39]. EEG-based emotion signals (excitement, frustration, engagement/boredom and meditation) are characterized as reliable and quick response signals. Therefore, it is relevant to construct and investigate methods and models of recognition and estimation dependencies between emotion signals and different stimuli and to design the emotion feedback systems based on these models [29], [31], [43].

Linear and nonlinear predictive models of the input-output structure were proposed and investigated for exploring dependencies of the EEG-based emotion signals as a human response to a dynamic virtual 3D face features when a virtual 3D face is observed without a virtual reality headset [24], [26], [46]. The technique of dynamic systems identification which ensures stability of the models is applied to build these models [14].

Predictive models are necessary in the design of predictor-based control systems [5], [6], [7], [15-17], [37]. Predictor-based control principles were applied to the control of human emotion signals when a 3D face was observed without a virtual reality headset [25], [27].

In this paper, three predictor-based control schemes with a minimum variance or a generalized minimum variance control quality, constrained control signal magnitude and changing rate are developed for the control of human excitement as response to a dynamic 3D face when it is observed using virtual reality headset. The first results of experiments in this direction were published in [28]. Different generalized minimum variance control criterion is used in this paper. Stability and systematic control error of the closed loop system are investigated. Selection of the weight coefficient of a generalized minimum variance criterion is based on stability condition of closed loop system and admissible value of systematic control error. The technique of systems identification which ensures stability and possible higher gain of the predictive models of the control plant is applied. Moreover, quantity of volunteers is expanded on purpose to increase reliability of the experimental control schemes comparison results.

\section{Control Plant}

A virtual 3D face of woman was used as a stimulus for eliciting human reaction. Three types of 3D face features (distance-between-eyes, nose width and chin width) were used for human reaction elicitation and four EEG-based response signals (excitement, frustration, engagement/boredom and meditation) were observed and analyzed in previous research [46]. Analysis of the results has shown that all three types of the $3 \mathrm{D}$ face feature have triggered similar human reaction signals, accordingly distance-between-eyes was selected and used as a dynamic 3D face feature in further research [24], [26], [28]. From observed four EEG-based response signals, excitement is the most variable signal. A virtual 3D face of woman with changing distance-between-eyes was used for input (control signal) and EEG-based pre-processed excitement signal was measured as output (Figure 1) in this research. The output signal was recorded with Emotiv Epoc device. This device records EEG inputs from 14 channels (in accordance with the international 10-20 locations): AF3, Fr7, F3, FC5, T7, P7, O1, O2, P8, T8, FC6, F4, F8, AF4 [34]. Values of the excitement signal vary from 0 to 1 . If excitement is low, the value is close to 0 and if it is high, the value is close to 1 .

\section{Figure 1}

Input - Output Control Plant

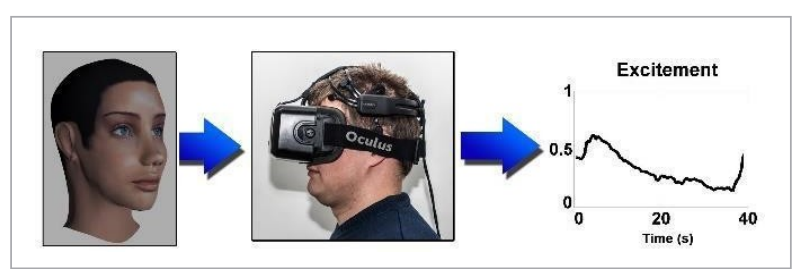

Other 3D faces were formed by changing distance-between-eyes in an extreme manner (Figure 2).

The transitions between normal and extreme stages were programmed. "Neutral" face has 0 value, largest distance-between-eyes corresponds to value 3 and smallest distance-between-eyes corresponds to value -3 . The excitement and changing distance-between-eyes signals were recorded with the sampling period of $\mathrm{T}_{0}=0.5$. 


\section{Figure 2}

A virtual 3D face of the woman with changing (the smallest (right), normal (middle) and the largest (left)) distancebetween-eyes

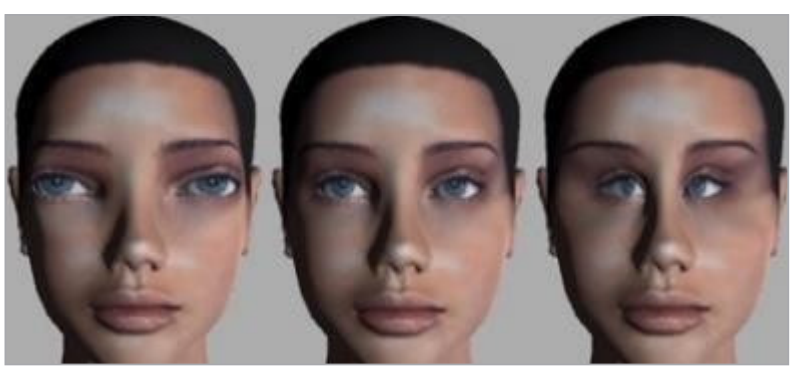

\section{Model Building}

Cross-correlation analysis demonstrated that there is a relative high correlation between observations of the EEG-based excitement signal and changing distance-between-eyes in virtual 3D face [28]. The shift of the maximum values of the cross-correlations in relation to the origin allows stating that there exist linear dynamic relations between input and output signals. Accordingly, dependency between human excitement as response to a virtual 3D face with changing distance-between-eyes is described by a linear input-output structure model [24]

$$
\mathrm{A}\left(\mathrm{z}^{-1}\right) \mathrm{y}_{\mathrm{t}}=\theta_{0}+\mathrm{B}\left(\mathrm{z}^{-1}\right) \mathrm{x}_{\mathrm{t}}+\varepsilon_{\mathrm{t}}
$$

where

$$
\begin{aligned}
& A\left(z^{-1}\right)=1+\sum_{i=1}^{n} a_{i} z^{-i}, \\
& B\left(z^{-1}\right)=\sum_{j=0}^{m} b_{j} z^{-j}, \quad m \leq n,
\end{aligned}
$$

$\mathrm{y}_{\mathrm{t}}$ is an output (excitement), $\mathrm{x}_{\mathrm{t}}$ is input (distance-between-eyes) signals, respectively, observed as

$$
\mathrm{y}_{\mathrm{t}}=\mathrm{y}\left(\mathrm{tT}_{0}\right), \mathrm{x}_{\mathrm{t}}=\mathrm{x}\left(\mathrm{tT}_{0}\right)
$$

with a sampling period $\mathrm{T}_{0}, \varepsilon_{\mathrm{t}}$ denotes the equation error of white-noise type, $\mathrm{z}^{-1}$ is the backward-shift operator $\left(\mathrm{z}^{-1} \mathrm{x}_{\mathrm{t}}=\mathrm{x}_{\mathrm{t}-1}\right)$ and $\theta_{0}$ is a constant value.

Model (1) with permanent component $\theta_{0}>0$, which evaluates that excitement signal is positive, is different from ordinary linear dynamic model.
Equation (1) can be expressed in the following form

$\mathrm{y}_{\mathrm{t}}=\mathrm{y}_{\mathrm{t} \mid \mathrm{t}-1}+\varepsilon_{\mathrm{t}}$,

where

$\mathrm{y}_{\mathrm{t} t \mathrm{t}-1}=\theta_{0}+\mathrm{z}\left[1-\mathrm{A}\left(\mathrm{z}^{-1}\right)\right] \mathrm{y}_{\mathrm{t}-1}+\mathrm{B}\left(\mathrm{z}^{-1}\right) \mathrm{x}_{\mathrm{t}}$

is one-step-ahead output prediction model, $\mathrm{z}$ is a toward-shift operator $\left(\mathrm{zy}_{\mathrm{t}}=\mathrm{y}_{\mathrm{t}+1}\right)$.

Parameters (coefficients $b_{j}$ and $\mathrm{a}_{\mathrm{i}}$, degrees $m$ and $n$ of the polynomials (2) and constant $\theta_{0}$ ) of the model (1) are unknown. They must be estimated in the identification process, according to the observations obtained during the experiments with the volunteers.

Basic techniques of system identification and numerical schemes of computing the estimates [8], [9], [32], [40] do not ensure stability of the dynamic models. As a solution to this problem, the techniques and numerical methods of dynamic system identification were developed [14].

Applying this technique, the current estimates of the parameters are obtained from the condition

$\widehat{\mathbf{c}}_{\mathrm{t}}: \widetilde{\mathrm{Q}}_{\mathrm{t}}(\mathbf{c})=\frac{1}{\mathrm{t}-\mathrm{n}} \sum_{\mathrm{k}=\mathrm{n}+1}^{\mathrm{t}} \varepsilon_{\mathrm{k} \mid \mathrm{k}-1}^{2}(\mathbf{c}) \rightarrow \min _{\mathrm{c} \in \Omega_{\mathrm{c}}}$

where

$\mathbf{c}^{\mathrm{T}}=\left[\theta_{0}, \mathrm{~b}_{\mathrm{o}}, \mathrm{b}_{1}, \ldots, \mathrm{b}_{\mathrm{m}}, \mathrm{a}_{1}, \mathrm{a}_{2}, \ldots, \mathrm{a}_{\mathrm{n}}\right]$

is a vector of the coefficients of the polynomials (2) and parameter $\theta_{0}$,

$\varepsilon_{t+1 \mid t}(c)=y_{t+1}-y_{t+1 \mid t}$

is one-step-ahead output prediction error,

$\Omega_{\mathrm{c}}=\left\{\mathrm{a}_{\mathrm{i}}: \quad\left|\mathrm{z}_{\mathrm{i}}^{\mathrm{A}}\right|<1, \mathrm{i}=1,2, \ldots, \mathrm{n}\right\}$

is stability domain (unity disk) for the model (1), $\mathrm{z}_{\mathrm{i}}^{\mathrm{A}}$ are the roots of the polynomial

$$
\begin{gathered}
\mathrm{z}_{\mathrm{i}}^{\mathrm{A}}: \mathrm{A}(\mathrm{z})=0, \quad \mathrm{i}=1, \ldots, \mathrm{n}, \\
\mathrm{A}(\mathrm{z})=\mathrm{z}^{\mathrm{n}} \mathrm{A}\left(\mathrm{z}^{-1}\right)
\end{gathered}
$$

$T$ is a vector transpose sign, sign || denotes the absolute value. 
The numerical algorithms for computing the estimates as a solution of the minimization problem (5)(9) were investigated in [24], [26], [28].

\section{Control with Constraints Schemes}

The control law synthesis for stochastic control plant (1) is often based on minimizing variance of the deviation between the observed output signal and the reference signal (minimum variance control) [1], [12], [41]. Generalized minimum variance control is obtained by introducing control costing [2], [4], [6, 7], [37], [42].

Basic techniques of a minimum variance or generalized minimum variance control are developed without evaluation of possible control signal constraints. Accordingly, techniques and schemes with constrained control signal magnitude and change rate for linear and nonlinear plants were constructed [15-23]. Applying this technique for the control plant (1), the control law is obtained from the condition

$$
\begin{aligned}
& \mathrm{x}_{\mathrm{t}+1}^{*}: \mathrm{Q}_{\mathrm{t}}\left(\mathrm{x}_{\mathrm{t}+1}\right) \rightarrow \min _{\mathrm{x}_{\mathrm{t}+1} \in \Omega_{\mathrm{x}}}, \\
& \mathrm{Q}_{\mathrm{t}}\left(\mathrm{x}_{\mathrm{t}+1}\right)=\mathrm{E}\left\{\left(\mathrm{y}_{\mathrm{t}+1}-\mathrm{y}_{\mathrm{t}+1}^{*}\right)^{2}+\mathrm{q}\left(\mathrm{x}_{\mathrm{t}+1}-\mathrm{u}_{\mathrm{t}+1}\right)^{2}\right\}, \\
& \Omega_{\mathrm{x}}=\left\{\mathrm{x}_{\mathrm{t}+1}: \mathrm{x}_{\min } \leq \mathrm{x}_{\mathrm{t}+1} \leq \mathrm{x}_{\max },\left|\mathrm{x}_{\mathrm{t}+1}-\mathrm{x}_{\mathrm{t}}^{*}\right| \leq \delta_{\mathrm{t}}\right\}
\end{aligned}
$$

where $E$ is an expectation operator, $\mathrm{y}_{\mathrm{t}+1}^{*}$ is a reference output signal (reference trajectory for excitement), $\mathrm{u}_{\mathrm{t}+1}$ marks the reference trajectory for the control signal (distance-between-eyes), $\mathrm{x}_{\min }$ and $\mathrm{x}_{\max }$ are control signal boundaries (smallest and largest distance-between-eyes), $\delta_{t}>0$ are the restriction values for the change rate of the control signal, sign | | denotes absolute value, and $q \geq 0$ is weight coefficient.

Then solving the minimization problem (10)-(12) for one-step ahead prediction model (4), the control law is described by equation

$$
\mathrm{x}_{\mathrm{t}+1}^{*}=\left\{\begin{array}{r}
\min \left\{\mathrm{x}_{\max }, \mathrm{x}_{\mathrm{t}}^{*}+\delta_{\mathrm{t}}, \tilde{\mathrm{x}}_{\mathrm{t}+1}\right\}, \\
\text { if } \tilde{\mathrm{x}}_{\mathrm{t}+1} \geq \mathrm{x}_{\mathrm{t}}^{*}, \\
\max \left\{\mathrm{x}_{\min }, \mathrm{x}_{\mathrm{t}}^{*}-\delta_{\mathrm{t}}, \tilde{\mathrm{x}}_{\mathrm{t}+1}\right\}, \\
\text { if } \tilde{\mathrm{x}}_{\mathrm{t}+1}<\mathrm{x}_{\mathrm{t}}^{*},
\end{array}\right.
$$

$\widetilde{\mathrm{B}}\left(\mathrm{z}^{-1}\right) \tilde{\mathrm{x}}_{\mathrm{t}+1}=-\mathrm{L}\left(\mathrm{z}^{-1}\right) \mathrm{y}_{\mathrm{t}}+\mathrm{y}_{\mathrm{t}+1}^{*}-\theta_{0}+\lambda \mathrm{u}_{\mathrm{t}+1}$,
$\mathrm{L}\left(\mathrm{z}^{-1}\right)=\mathrm{z}\left[1-\mathrm{A}\left(\mathrm{z}^{-1}\right)\right]$

$\widetilde{\mathrm{B}}\left(\mathrm{z}^{-1}\right)=\lambda+\mathrm{B}\left(\mathrm{z}^{-1}\right), \quad \lambda=\mathrm{q} / \mathrm{b}_{0}$.

If the roots of polynomial

$$
\widetilde{\mathrm{B}}(\mathrm{z})=\mathrm{z}^{\mathrm{m}} \widetilde{\mathrm{B}}\left(\mathrm{z}^{-1}\right)
$$

are in the unity disk

$\left|z_{j}^{B}\right|<1, \quad z_{j}^{B}: \widetilde{B}(z)=0, j=1, \ldots, m$,

then from (14) and (16) the following equation is correct

$$
\tilde{x}_{t+1}=\frac{1}{b_{0}+\lambda}\left\{\sum_{i=1}^{n} a_{i} y_{t+1-i}-\sum_{j=1}^{m} b_{j} x_{t+1-j}^{*}-\theta_{0}+y_{t+1}^{*}+\lambda u_{t+1}\right\} .
$$

If a part or all of polynomial (17) roots do not belong to the unity disk, weight factor $|\lambda|$ (weight coefficient in (11)) needs to be increased until all roots are in the unity disk.

When inserting the control signal, which is described by Equation (14), to the model (1), we get a closedloop system equation

$\left[\mathrm{B}\left(\mathrm{z}^{-1}\right)+\lambda \mathrm{A}\left(\mathrm{z}^{-1}\right)\right] \mathrm{y}_{\mathrm{t}}=\lambda \theta_{0}+\mathrm{B}\left(\mathrm{z}^{-1}\right)\left(\mathrm{y}_{\mathrm{t}}^{*}+\lambda \mathrm{u}_{\mathrm{t}}\right)+\left(\mathrm{B}\left(\mathrm{z}^{-1}\right)+\lambda\right) \varepsilon_{\mathrm{t}}$

It is clear from Equation (20) that stability of the closed-loop system is dependent on characteristic polynomial roots

$$
\begin{aligned}
& \mathrm{D}(\mathrm{z})=\mathrm{z}^{\mathrm{n}} \mathrm{D}\left(\mathrm{z}^{-1}\right), \\
& \mathrm{D}\left(\mathrm{z}^{-1}\right)=\mathrm{B}\left(\mathrm{z}^{-1}\right)+\lambda \mathrm{A}\left(\mathrm{z}^{-1}\right),
\end{aligned}
$$

all roots must be inside the unity disk

$$
\left|z_{i}^{D}\right| \leq 1, \quad z_{i}^{D}: \quad D(z)=0, \quad i=1,2, \ldots, n .
$$

The analysis of characteristic polynomial Equation (21) allows to state that having a stable model in the process of the identification (5)-(9), stability of a closed-loop system is obtained with any arrangement of roots of the polynomial $\mathrm{B}\left(\mathrm{z}^{-1}\right)$, when the weight factor $|\lambda|$ is increased. 
From Equation (20), we get the permanent component of output signal in stationary regime $\left(\mathrm{y}_{\mathrm{t}}^{*}=\mathrm{y}^{*}, \mathrm{u}_{\mathrm{t}}=\mathrm{u}^{*}\right)$ is

$$
\mathrm{y}=\mathrm{K}_{\mathrm{p}}\left(\mathrm{y}^{*}+\widetilde{\theta}_{0}+\lambda \mathrm{u}^{*}\right), \tilde{\theta}_{0}=\frac{\lambda \theta_{0}}{\mathrm{~B}(1)},
$$

where

$$
\mathrm{K}_{\mathrm{p}}=\frac{\mathrm{B}(1)}{\mathrm{B}(1)+\lambda \mathrm{A}(1)}
$$

is a gain of the transfer function of the reference signal $\mathrm{y}_{\mathrm{t}}^{*}$ in a closed - loop

$$
\mathrm{W}_{\mathrm{p}}\left(\mathrm{z}^{-1}\right)=\frac{\mathrm{B}\left(\mathrm{z}^{-1}\right)}{\mathrm{B}\left(\mathrm{z}^{-1}\right)+\lambda \mathrm{A}\left(\mathrm{z}^{-1}\right)} .
$$

Considering the expression (24), the weight factor is calculated by equation

$$
\lambda=\frac{\mathrm{K}_{0}\left(1-\mathrm{K}_{\mathrm{p}}\right)}{\mathrm{K}_{\mathrm{p}}} \text {, }
$$

$$
\text { where }
$$

$$
\mathrm{K}_{0}=\frac{\mathrm{B}(1)}{\mathrm{A}(1)}
$$

is a gain of the transfer function of the input-output model (1)

$$
\mathrm{W}_{0}\left(\mathrm{z}^{-1}\right)=\frac{\mathrm{B}\left(\mathrm{z}^{-1}\right)}{\mathrm{A}\left(\mathrm{z}^{-1}\right)} .
$$

From Equation (23) follows systematic control error

$$
e_{p}=y^{*}-y=\left(1-K_{p}\right) y^{*}-K_{p}\left(\tilde{\theta}_{o}+\lambda u^{*}\right)
$$

grows if $\mathrm{K}_{\mathrm{p}}$ is significantly lower than unit (weight factor $|\lambda|$ in Equation (16) or (19) of the control law or weight coefficient $q$ in control criterion (11) is high).

The gain $\mathrm{K}_{\mathrm{p}}$ is selected from an interval

$$
\begin{aligned}
\mathrm{K}_{\mathrm{p}} \in[0.8,1], \text { if }\left(\mathrm{b}_{0}>0\right) & \wedge\left(\mathrm{K}_{0}>0\right) \text { or } \\
\left(\mathrm{b}_{0}<0\right) & \wedge\left(\mathrm{K}_{0}<0\right)
\end{aligned}
$$

or

$$
\begin{aligned}
& \mathrm{K}_{\mathrm{p}} \in[1,1.2], \text { if }\left(\mathrm{b}_{0}>0\right) \wedge\left(\mathrm{K}_{0}<0\right) \text { or } \\
&\left(\mathrm{b}_{0}<0\right) \wedge\left(\mathrm{K}_{0}>0\right) .
\end{aligned}
$$

When $\mathrm{K}_{\mathrm{p}}=1(\lambda=0, q=0)$, we get a minimum variance control, in other cases - a generalized minimum variance control quality. In this research, generalized minimum variance control, when

$$
\mathrm{u}_{\mathrm{t}+1}=\mathrm{x}_{\mathrm{t}}^{*} \text { (the first scheme), } \mathrm{t}=1,2, \ldots
$$

or

$$
\mathrm{u}_{\mathrm{t}+1}=0 \text { (the second scheme), } \mathrm{t}=1,2, \ldots
$$

and minimum variance control are compared.

The structures of a minimum variance and generalized minimum variance controllers with constraints are illustrated in Figures 3-5.

\section{Figure 3}

The first scheme of a constrained generalized minimum variance control (13)-(16) and (32)

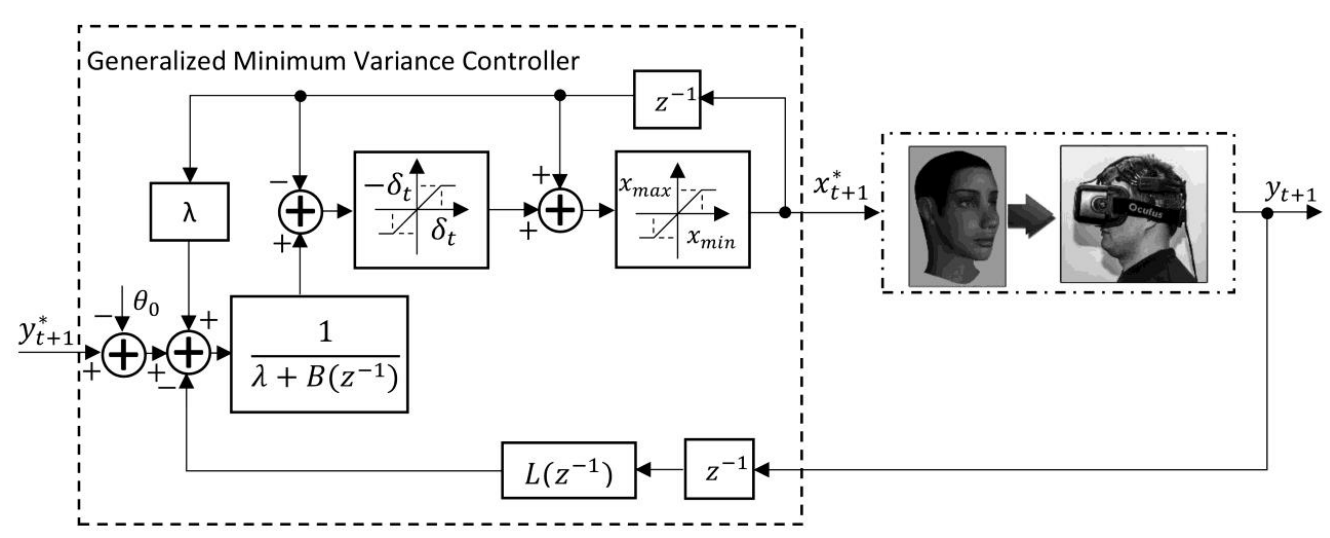




\section{Figure 4}

The second scheme of a constrained generalized minimum variance control (13)-(16) and (33)

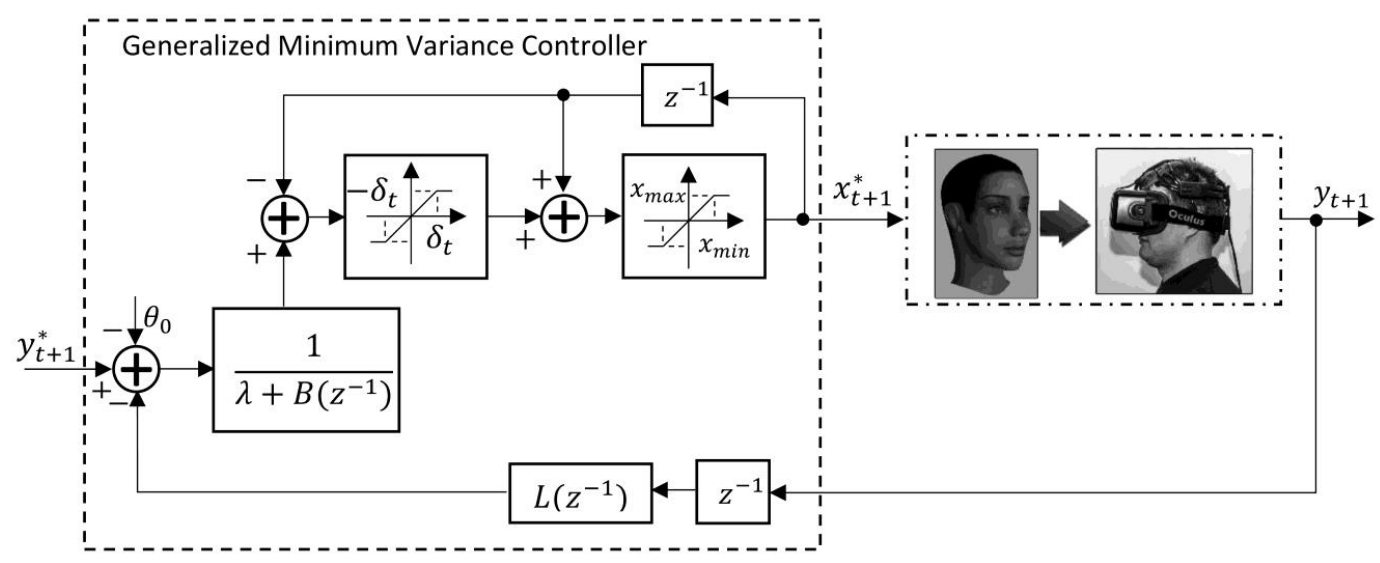

Figure 5

The scheme of a constrained minimum variance control (13)-(16) and $\lambda=0$

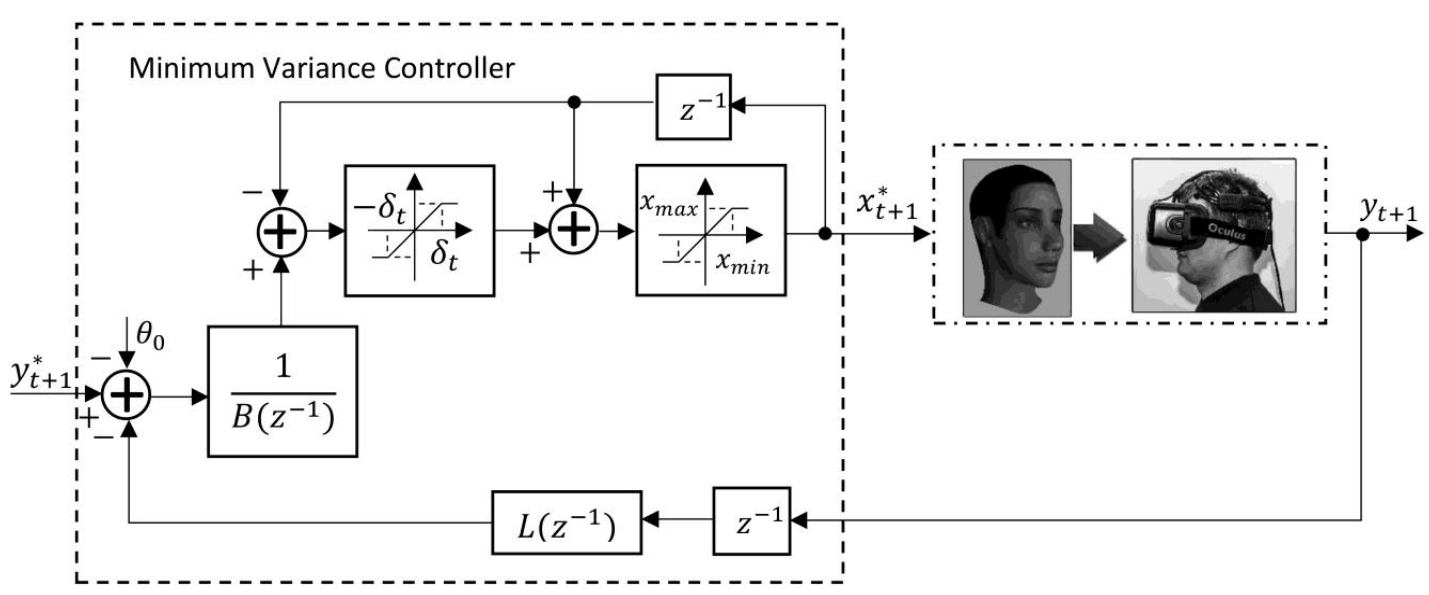

Directly implicit predictive model (4) was used only for the solution of the optimization problem (10)-(12) in the law of a generalized minim variance control (13)-(16). Predictive model may also be constructed as [15-17], [23]

$\mathrm{A}\left(\mathrm{z}^{-1}\right) \mathrm{y}_{\mathrm{t}+1 \mid \mathrm{t}}=\theta_{0}+\mathrm{B}\left(\mathrm{z}^{-1}\right) \mathrm{x}_{\mathrm{t}+1}+\mathrm{z}\left[1-\mathrm{A}\left(\mathrm{z}^{-1}\right)\right] \varepsilon_{\mathrm{t} \mid \mathrm{t}-1}$, where

$\varepsilon_{\mathrm{t} \mid \mathrm{t}-1}=\mathrm{y}_{\mathrm{t}}-\mathrm{y}_{\mathrm{t} \mid \mathrm{t}-1}$

is one-step-ahead output prediction error. Then, in control law (13)-(16), Equations (14) and (16) are replaced by the following equations, respectively, 
Figure 6

The scheme of a constrained generalized minimum variance control with predictor

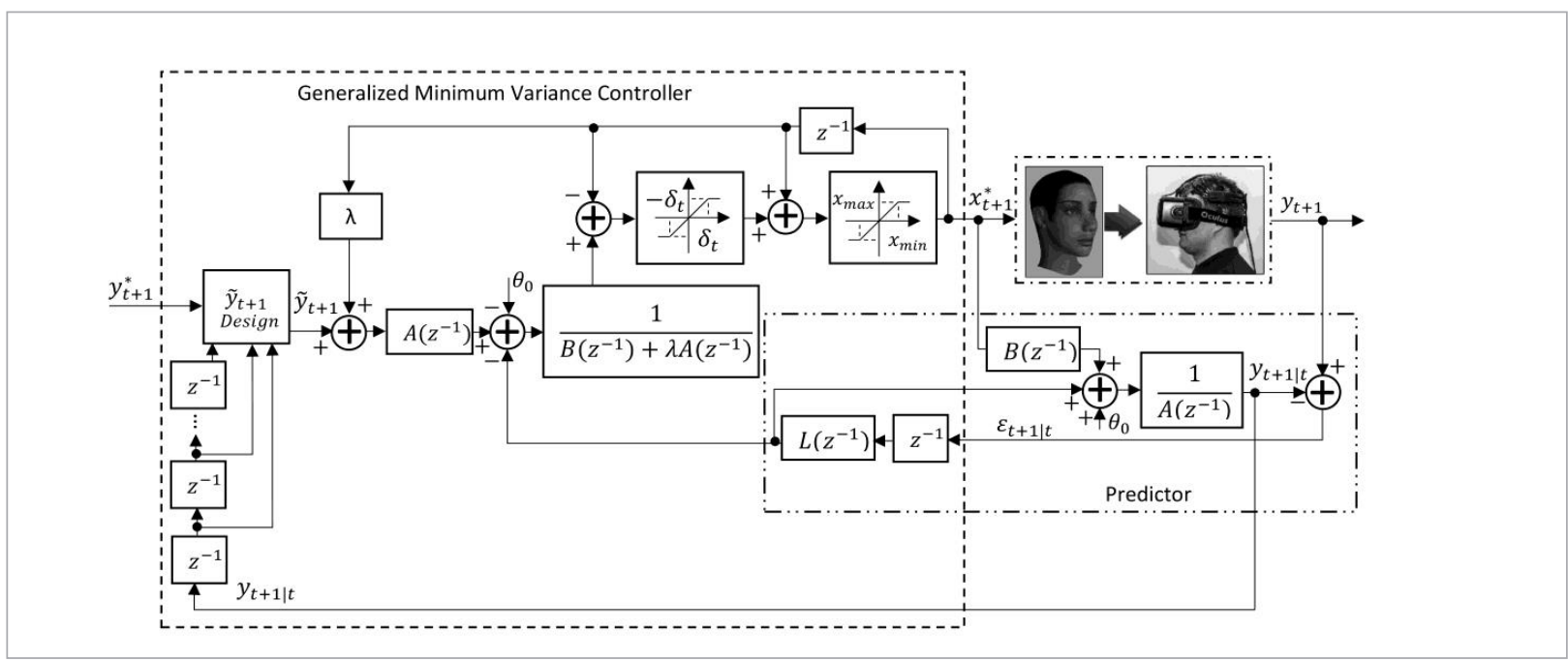

$$
\begin{aligned}
& \widetilde{\mathrm{B}}\left(\mathrm{z}^{-1}\right) \tilde{\mathrm{x}}_{\mathrm{t}+1}=-\mathrm{L}\left(\mathrm{z}^{-1}\right) \varepsilon_{\mathrm{t} \mid \mathrm{t}-1}-\theta_{0}+\mathrm{A}\left(\mathrm{z}^{-1}\right)\left(\tilde{\mathrm{y}}_{\mathrm{t}+1}+\lambda \mathrm{u}_{\mathrm{t}+1}\right) \\
& \widetilde{\mathrm{B}}\left(\mathrm{z}^{-1}\right)=\mathrm{B}\left(\mathrm{z}^{-1}\right)+\lambda \mathrm{A}\left(\mathrm{z}^{-1}\right)
\end{aligned}
$$

where

$$
\tilde{y}_{\mathrm{k}+1}= \begin{cases}\mathrm{y}_{\mathrm{k}+1,}^{*}, & \text { if } \mathrm{k}=\mathrm{t}, \\ \mathrm{y}_{\mathrm{k}+1 \mid \mathrm{k},} & \text { if } \mathrm{k}=\mathrm{t}-1, \ldots, \mathrm{t}-\mathrm{n}\end{cases}
$$

is a modified reference signal, considering that onestep-ahead output prediction could not reach a reference signal due to the restrictions to the control signal.

The scheme of a constrained generalized minimum variance with predictor control (13), (15), (32) and (34)-(38) is illustrated in Figure 6. Predictive model (4) for predictor design could be also used in this scheme [15-17].

Consequently, in this case, predictive model is a basic structural element of a minimum variance or generalized minimum variance control schemes [15], [21-23]. Accordingly, this type of control is named as predictor-based control [6], [7], [15-17], [37].

Because control signal $\mathrm{x}_{\mathrm{t}}^{*} \in\left[\mathrm{x}_{\min }, \mathrm{x}_{\max }\right]$, the largest value of permanent component in output signal of control plant (1) is

$$
\mathrm{y}_{\max }=\mathrm{K}_{0} \mathrm{x}_{\max }+\frac{1}{\mathrm{~A}(1)} \theta_{0}, \text { if } \mathrm{K}_{0}>0
$$

or

$$
\mathrm{y}_{\max }=\mathrm{K}_{0} \mathrm{x}_{\min }+\frac{1}{\mathrm{~A}(1)} \theta_{0} \text {, if } \mathrm{K}_{0}<0
$$

Accordingly, reference output signal must not exceed $\mathrm{y}_{\max }\left(\mathrm{y}_{\mathrm{t}}^{*} \leq \mathrm{y}_{\max }\right)$.

\section{Modeling Results}

Modelling experiments consisted of two phases. In the first phase, human excitement signals as response to $3 \mathrm{D}$ face with changing distance-between-eyes (testing input, Figure 7) were observed [25]. Fifteen volunteers (five females and ten males) were tested. Each volunteer was watching a changing virtual 3D face with a virtual reality headset, and each experiment was approximately $100 \mathrm{~s}$ long. EEG-based and changing distance-between eyes signals were measured with sampling period $\mathrm{T}_{0}=0.5 \mathrm{~s}$ and recorded in real time (for each signal, the number of observations is $\mathrm{N}=185$ ).

The first observations (until $t \leq 120$ ) for each volunteer (Table. 1) were used for computing the current estimates of parameters of the predictive models (4). For evaluation of the model order and prediction accuracy, all observations were used.

Each predictive model is selected from twelve possi- 
Figure 7

Testing input

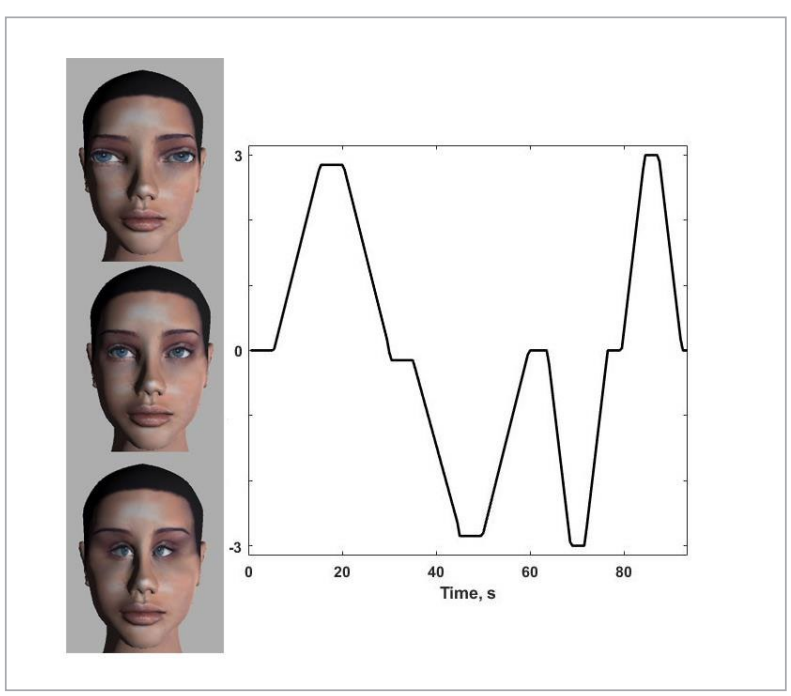

Table 1

Parameter estimates of the model (41), average absolute prediction error (43), number $t$ of the observations used for the model building with gain (42) and maximum values values $r_{x y}$ of the cross-correlation functions

\begin{tabular}{c|c|c|c|c|c|c|c}
\multicolumn{2}{c|}{$\begin{array}{c}\text { Volunteer } \\
\text { No. }\end{array}$} & $\hat{\theta}_{0}$ & $\hat{\mathrm{b}}_{0}$ & $\hat{\mathrm{a}}_{1}$ & $|\bar{\varepsilon}|$ & $\mathrm{t}$ & $\mathrm{r}_{\mathrm{xy}}$ \\
\hline 1 & Female & 0.0400 & -0.0067 & -0.9567 & $10.1 \%$ & 100 & 0.61 \\
\hline 2 & Female & 0.0405 & -0.0117 & -0.9444 & $6.8 \%$ & 120 & 0.86 \\
\hline 3 & Female & 0.0367 & -0.0129 & -0.9633 & $6.4 \%$ & 50 & 0.91 \\
\hline 4 & Female & 0.0274 & 0.0092 & -0.8968 & $7.2 \%$ & 30 & 0.66 \\
\hline 5 & Female & 0.0151 & 0.0029 & -0.9701 & $7.2 \%$ & 80 & 0.69 \\
\hline 6 & Male & 0.0467 & -0.0171 & -0.9764 & $9.5 \%$ & 50 & 0.86 \\
\hline 7 & Male & 0.0294 & 0.0078 & -0.8014 & $8.0 \%$ & 20 & 0.55 \\
\hline 8 & Male & 0.0411 & -0.0089 & -0.9896 & $7.5 \%$ & 90 & 0.76 \\
\hline 9 & Male & 0.0186 & -0.0049 & -0.9512 & $4.6 \%$ & 50 & 0.85 \\
\hline 10 & Male & 0.0336 & -0.0064 & -0.9766 & $10.4 \%$ & 70 & 0.81 \\
\hline 11 & Male & 0.0303 & -0.0090 & -0.9890 & $8.1 \%$ & 70 & 0.82 \\
\hline 12 & Male & 0.0399 & -0.0092 & -0.8718 & $9.7 \%$ & 40 & 0.77 \\
\hline 13 & Male & 0.0391 & -0.0031 & -0.9840 & $5.7 \%$ & 120 & 0.76 \\
\hline 14 & Male & 0.0224 & -0.0092 & -0.9021 & $7.3 \%$ & 60 & 0.70 \\
\hline 15 & Male & 0.0252 & -0.0058 & -0.9934 & $7.3 \%$ & 100 & 0.83 \\
\hline & & & & & \\
\hline
\end{tabular}

ble models (when $\mathrm{n}=1,2,3, \mathrm{~m}=0,1,2,3$ ). The analysis of the identification results showed that the relations between excitement and distance-between-eyes can be described using the first order $(\widehat{m}=0, \hat{n}=1)$ predictive model

$$
\hat{y}_{t+1 \mid t}=\widehat{\theta}_{0}+\widehat{b}_{0} x_{t+1}-\hat{a}_{1} y_{t}, \quad t=1,2, \ldots
$$

From Equations (39)-(40) it is clear that to build a predictive model for control system it is necessary to consider not only the output prediction accuracy, but also the gain (27) of the transfer function (28). Accordingly, the current estimates of the parameters (5) are calculated for $t=\rho, \rho+1, \ldots, \tilde{N}$, where $\rho>2 n+m+3$ is the first value of discrete time $t$ when testing signal value is not equal to zero. In this way, we get subset $\Omega_{\mathrm{K}}$ with gain (27) values $\mathrm{K}_{\mathrm{t}}$ where change of predictor accuracy measure is small. From this subset, we choose predictive model with

$$
\widehat{\mathrm{K}}_{0}=\max \left\{\left|\mathrm{K}_{\mathrm{t}}\right|, \mathrm{K}_{\mathrm{t}} \in \Omega_{\mathrm{K}}\right\} .
$$

Prediction accuracies were evaluated using the average absolute relative prediction error

$$
|\bar{\varepsilon}|=\frac{1}{N-n} \sum_{t=n}^{N-1}\left|\frac{y_{t+1}-\hat{y}_{t+1 \mid t}}{y_{t+1}}\right| \times 100 \%
$$

Parameter estimates of the predictive model (41), predictor accuracy measure (43), discrete time t correspondent to current predictive model with gain (42) (number t of the observations used for the model building) and the maximum values of the cross-correlation functions

$$
\mathrm{r}_{\mathrm{yx}}=\max _{\tau}\left|\frac{\mathrm{R}_{\mathrm{yx}}[\tau]}{\sqrt{\mathrm{R}_{\mathrm{yy}}[0] \mathrm{R}_{\mathrm{xx}}[0]}}\right|
$$

are provided in Table 1. The examples of one-stepahead excitement prediction results are illustrated in Figure 8.

In the second phase, dynamical virtual 3D face is formed according to the control signal (13) and (19) (control input).

Reference signals were selected to maintain high ex- 


\section{Figure 8}

Examples of one-step-ahead excitement prediction results for female (upper, volunteer No. 4), and for male (lower, volunteer No. 10)

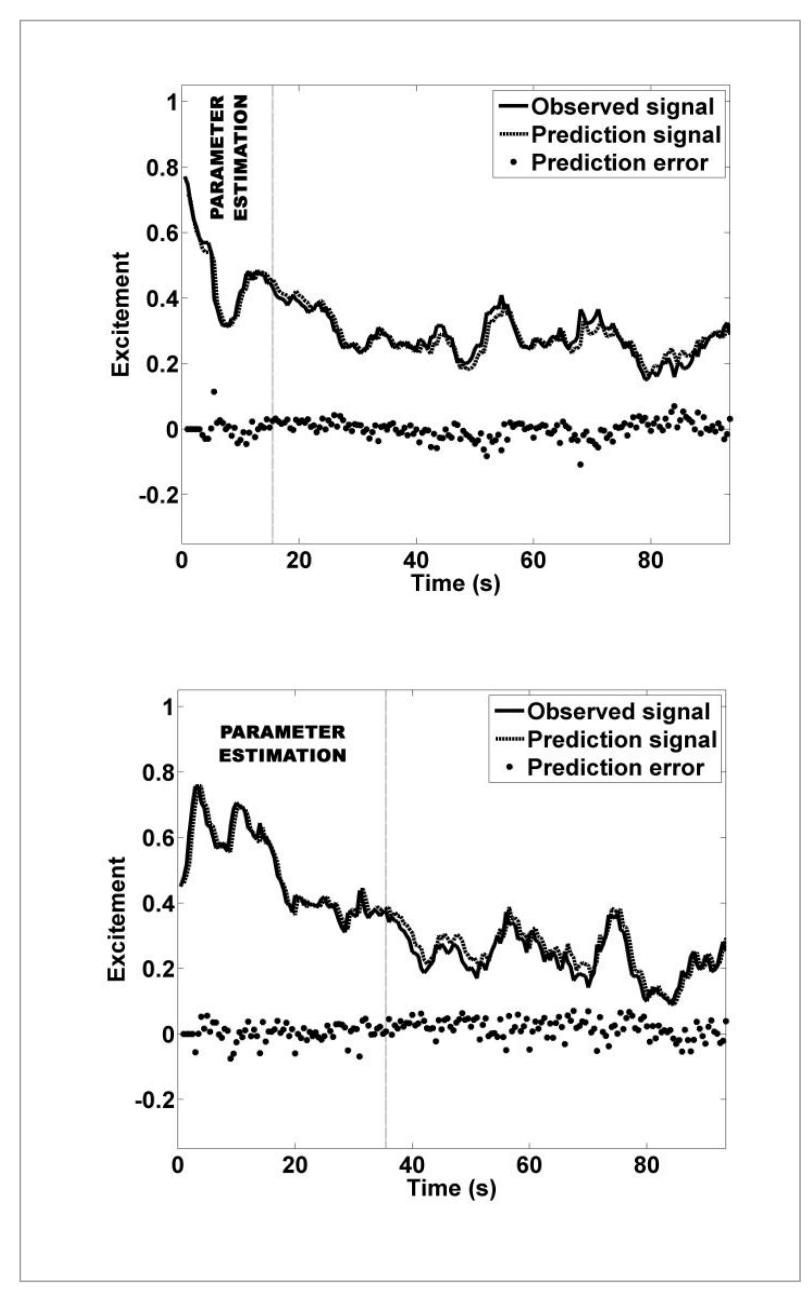

citement levels. In this case, a control efficiency for each volunteer can be evaluated by relative measures:

$$
\Delta y=\frac{\left|\overline{\mathrm{y}}_{\mathrm{C}}-\overline{\mathrm{y}}_{\mathrm{T}}\right|}{\overline{\mathrm{y}}_{\mathrm{T}}} \times 100 \%,
$$

$$
|\Delta y|=\frac{1}{N-n} \sum_{t=n}^{N-1}\left|\frac{\hat{y}_{t+1}-y_{t+1}^{*}}{y_{t+1}^{*}}\right| \times 100 \%
$$

where

$$
\overline{\mathrm{y}}_{\mathrm{T}}=\frac{1}{\mathrm{~N}-\mathrm{n}} \sum_{\mathrm{t}=\mathrm{n}}^{\mathrm{N}-1} \mathrm{y}_{\mathrm{t}+1}
$$

is the average of observed excitement signal as response to the testing input,

$\bar{y}_{C}=\frac{1}{N-n} \sum_{t=n}^{N-1} \hat{y}_{t+1}$

is the average of simulated output signal as response to the control signal (13) and (19)

$$
\begin{gathered}
\hat{y}_{t+1}=\hat{\theta}_{0}+\hat{b}_{0} x_{t+1}^{*}-\hat{a}_{1} \hat{y}_{t}+\widehat{\varepsilon}_{t+1}, \\
\hat{\varepsilon}_{t+1}=y_{t+1}-\hat{y}_{t+1 \mid t}, \hat{y}_{1}=y_{1}, t=1,2, . ., N .
\end{gathered}
$$

These average measures (44) and (45) are given in Tables 2 and 3. Examples of the excitement control results are demonstrated in Figures 9-13. The restriction values $\delta_{\mathrm{t}}$ for the change rate of the control signal are selected as: at the highest value $\delta_{\mathrm{t}}=6(12 / \mathrm{s})$, the control signal can pass from minimum $\mathrm{x}_{\min }$ to maximum value $\mathrm{x}_{\max }$ with one discrete time step $\mathrm{T}_{0}=0.5 \mathrm{~s}$ and vice versa, whereas at the smallest value $\delta_{\mathrm{t}}=0.15$ $(0.3 / \mathrm{s})$ control signal change speed is equivalent to the change rate of the testing signal (Figure 7 ).

Results of control efficiency in Table 2 demonstrate that compared to relative measure (44), all three control schemes assure sufficiently good control quality of excitement signal - maintained signal level is, on average, $83 \%$ (constrained minimum variance control and constrained generalized minimum variance with gain of closed-loop $\mathrm{K}_{\mathrm{p}}=0.95$ ) higher compared to a testing signal. Then gain decreases to $\mathrm{K}_{\mathrm{p}}=0.8$, efficiency of generalized minimum variance control decreases to about $80 \%$ for the first scheme and to about $70 \%$ for the second scheme.

This control efficiency is reached if limited control signal change speed is higher $-\delta_{t} \geq 1(2 / s)$. At lower signal change speed $-\delta_{\mathrm{t}} \geq 0.6(1.2 / \mathrm{s})$, control quality of excitement signal decreases from about $67 \%$ (minimum variance and the first scheme of generalized minimum variance control) to about $56 \%$ for the second scheme, when gain $K_{p}=0.8$. The first scheme is not sensitive to the decrease of the gain $\mathrm{K}_{\mathrm{p}}$ and is close to the scheme of constrained minimum variance control. 


\section{Table 2}

The average of the control efficiency measure (44) (after each $\delta_{t}$ value, upper row - the first scheme, lower - the second scheme of constrained generalized minimum variance control)

\begin{tabular}{|c|c|c|c|c|c|}
\hline$\delta_{t} \backslash K_{p}$ & 1 & 0.95 & 0.9 & 0.85 & 0.8 \\
\hline \multirow{2}{*}{6} & \multirow{2}{*}{$83.3 \%$} & $82.6 \%$ & $82.5 \%$ & $82.0 \%$ & $81.5 \%$ \\
\hline & & $80.9 \%$ & r7.7.\% & $73.8 \%$ & $69.5 \%$ \\
\hline \multirow{2}{*}{3} & \multirow{2}{*}{$83.0 \%$} & $82.6 \%$ & $82.5 \%$ & $82.0 \%$ & $81.6 \%$ \\
\hline & & $80.9 \%$ & 77.7.7\% & $73.8 \%$ & $69.4 \%$ \\
\hline \multirow{2}{*}{1} & \multirow{2}{*}{$81.0 \%$} & $80.8 \%$ & $80.8 \%$ & $80.3 \%$ & $80.0 \%$ \\
\hline & & $79.5 \%$ & $76.4 \%$ & $72.6 \%$ & $68.4 \%$ \\
\hline \multirow{2}{*}{0.6} & \multirow{2}{*}{$66.6 \%$} & $66.7 \%$ & $66.9 \%$ & $66.7 \%$ & $66.2 \%$ \\
\hline & & $65.9 \%$ & $63.0 \%$ & $59.7 \%$ & $56.1 \%$ \\
\hline \multirow{2}{*}{0.3} & \multirow{2}{*}{$67.6 \%$} & $66.8 \%$ & $66.8 \%$ & $67.1 \%$ & $67.2 \%$ \\
\hline & & $65.3 \%$ & $62.8 \%$ & $59.4 \%$ & $55.7 \%$ \\
\hline \multirow{2}{*}{0.15} & \multirow{2}{*}{$66.6 \%$} & $66.6 \%$ & $66.8 \%$ & $66.9 \%$ & $66.8 \%$ \\
\hline & & $65.4 \%$ & $63.0 \%$ & $59.2 \%$ & $55.4 \%$ \\
\hline
\end{tabular}

Table 3

The average of the control efficiency measure (45) (after each $\delta_{t}$ value, upper row - the first scheme, lower - the second scheme of constrained generalized minimum variance control)

\begin{tabular}{|c|c|c|c|c|c|}
\hline$\delta_{t} \backslash K_{p}$ & 1 & 0.95 & 0.9 & 0.85 & 0.8 \\
\hline \multirow{2}{*}{6} & \multirow{2}{*}{$13.0 \%$} & $13.9 \%$ & $14.5 \%$ & $15.1 \%$ & $15.8 \%$ \\
\hline & & $14.6 \%$ & $16.4 \%$ & $18.4 \%$ & $20.3 \%$ \\
\hline \multirow{2}{*}{3} & \multirow{2}{*}{$13.2 \%$} & $14.0 \%$ & $14.5 \%$ & $15.1 \%$ & $15.8 \%$ \\
\hline & & $14.6 \%$ & $16.4 \%$ & $18.4 \%$ & $20.3 \%$ \\
\hline \multirow{2}{*}{1} & \multirow{2}{*}{$14.8 \%$} & $14.9 \%$ & $15.2 \%$ & $15.6 \%$ & $16.2 \%$ \\
\hline & & $15.1 \%$ & $16.8 \%$ & $18.6 \%$ & $20.5 \%$ \\
\hline \multirow{2}{*}{0.6} & \multirow{2}{*}{$16.0 \%$} & $16.0 \%$ & $16.2 \%$ & $16.5 \%$ & $17.1 \%$ \\
\hline & & $15.7 \%$ & $17.3 \%$ & $19.1 \%$ & $21.0 \%$ \\
\hline \multirow{2}{*}{0.3} & \multirow{2}{*}{$20.0 \%$} & $20.2 \%$ & $20.4 \%$ & $20.5 \%$ & $20.7 \%$ \\
\hline & & $18.2 \%$ & $18.7 \%$ & $20.1 \%$ & $21.8 \%$ \\
\hline \multirow{2}{*}{0.15} & \multirow{2}{*}{$25.9 \%$} & $25.7 \%$ & $25.6 \%$ & $25.6 \%$ & $25.6 \%$ \\
\hline & & $23.5 \%$ & $22.0 \%$ & $22.2 \%$ & $23.3 \%$ \\
\hline
\end{tabular}

Results of control efficiency in Table 3 demonstrate that, compared to relative measure (45) (that characterizes average absolute relative control error), the first scheme of generalized control is not sensitive to the decrease of the gain $\mathrm{K}_{\mathrm{p}}$ if delta $\delta_{\mathrm{t}} \geq 0.6(1.2 / \mathrm{s})$. When limited signal change speed decreases $\left(\delta_{t} \leq 0.3\right)$, the average absolute relative control error grows and almost does not depend on change of the gain $\mathrm{K}_{\mathrm{p}}$, and all three schemes are equivalent.

Experiment results of the excitement control (Figures 9-13) demonstrated possibility to decrease variations of the control signal using a limited signal change speed (when constant $\delta_{t}$ of the admissible domain (12) decreases) or a generalized minimum variance control with lower gain $\mathrm{K}_{\mathrm{p}}$ (increasing weight factor $|\lambda|$ (26) in control law (13)-(16) or weight coefficient in criterion (11) is used). Variation of the control signal in the minimum variance control scheme is higher compared to variation in the first scheme at the same $\delta_{\mathrm{t}}$ values.

\section{Conclusions}

Experiment planning and cross correlation analysis results demonstrated that each volunteer reacted to the stimuli individually and response (EEG-based excitement signal) to dynamic virtual 3D face (with changing distance-between-eyes) can be described by the linear dynamic model (1) with different estimates of parameters. The numerical schemes of computing the current estimates of parameters are based on system identification technique which ensures stability and possible higher gain (42) of the model (1). Analysis of the results of a one-step-ahead prediction with the first order model (4) demonstrates that excitement signal can be predicted on average with about $8 \%$ average absolute relative prediction error (43). Accordingly, model (1) in the predictive form (4) can be applied to the design of predictor-based control system for stabilization of the excitement signal.

Three different schemes of the prediction-based control with constraints were developed for controlling a human excitement signal as response to a dynamic virtual 3D face. In these schemes, controllers design is based on minimum variance or generalized minimum 
Figure 9

Examples of excitement constrained generalized minimum variance control for volunteer No. 4 (female, the first scheme). Output: solid line denotes reference signal $y_{t}^{*}$, dotted line - simulated output signal $\hat{y}_{t}$ as response to the control signal, and dashed line - observed output $\mathrm{y}_{\mathrm{t}}$ as response to the testing input. Input: solid line denotes control signal $\mathrm{x}_{\mathrm{t}}^{*}$ and dashed lines denote testing input $\mathrm{x}_{\mathrm{t}}$
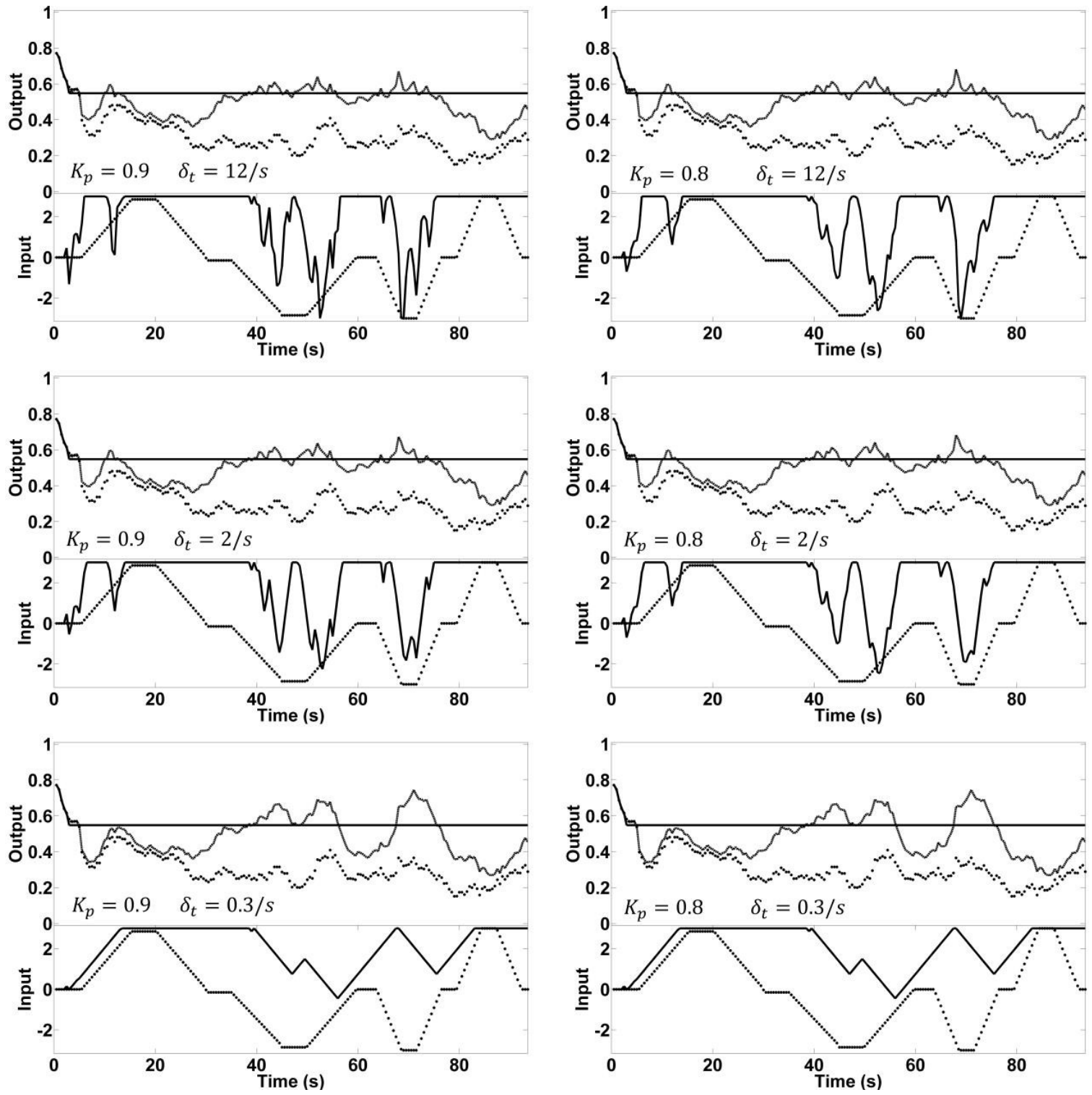
Figure 10

Examples of excitement constrained generalized minimum variance control for volunteer No. 4 (female, the second scheme). Output: solid line denotes reference signal $y_{t}^{*}$, dotted line - simulated output signal $\hat{y}_{t}$ as response to the control signal, and dashed line - observed output $\mathrm{y}_{\mathrm{t}}$ as response to the testing input. Input: solid line denotes control signal $\mathrm{x}_{\mathrm{t}}^{*}$ and dashed lines - testing input $\mathrm{x}_{\mathrm{t}}$
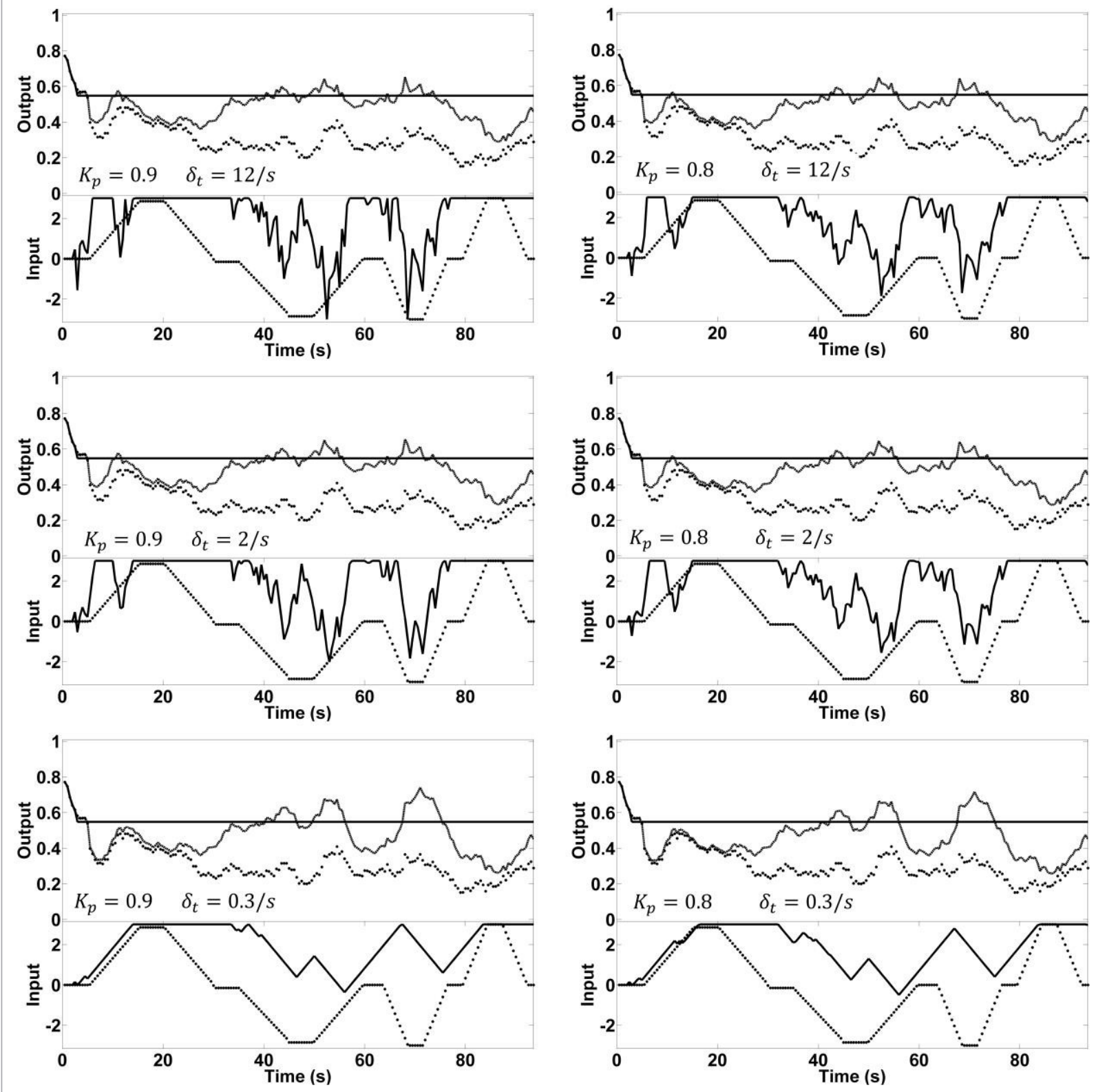
Figure 11

Examples of excitement constrained-generalized minimum variance control results with the first scheme for volunteer No. 10 (male, the first scheme). Output: solid line denotes reference signal $\mathrm{y}_{t}^{*}$, dotted line - simulated output signal $\hat{y}_{t}$ as response to the control signal, and dashed line - observed output $\mathrm{y}_{\mathrm{t}}$; as response to the testing input; Input: solid line denotes control signal $x_{t}^{*}$ and dashed lines - testing input $x_{t}$
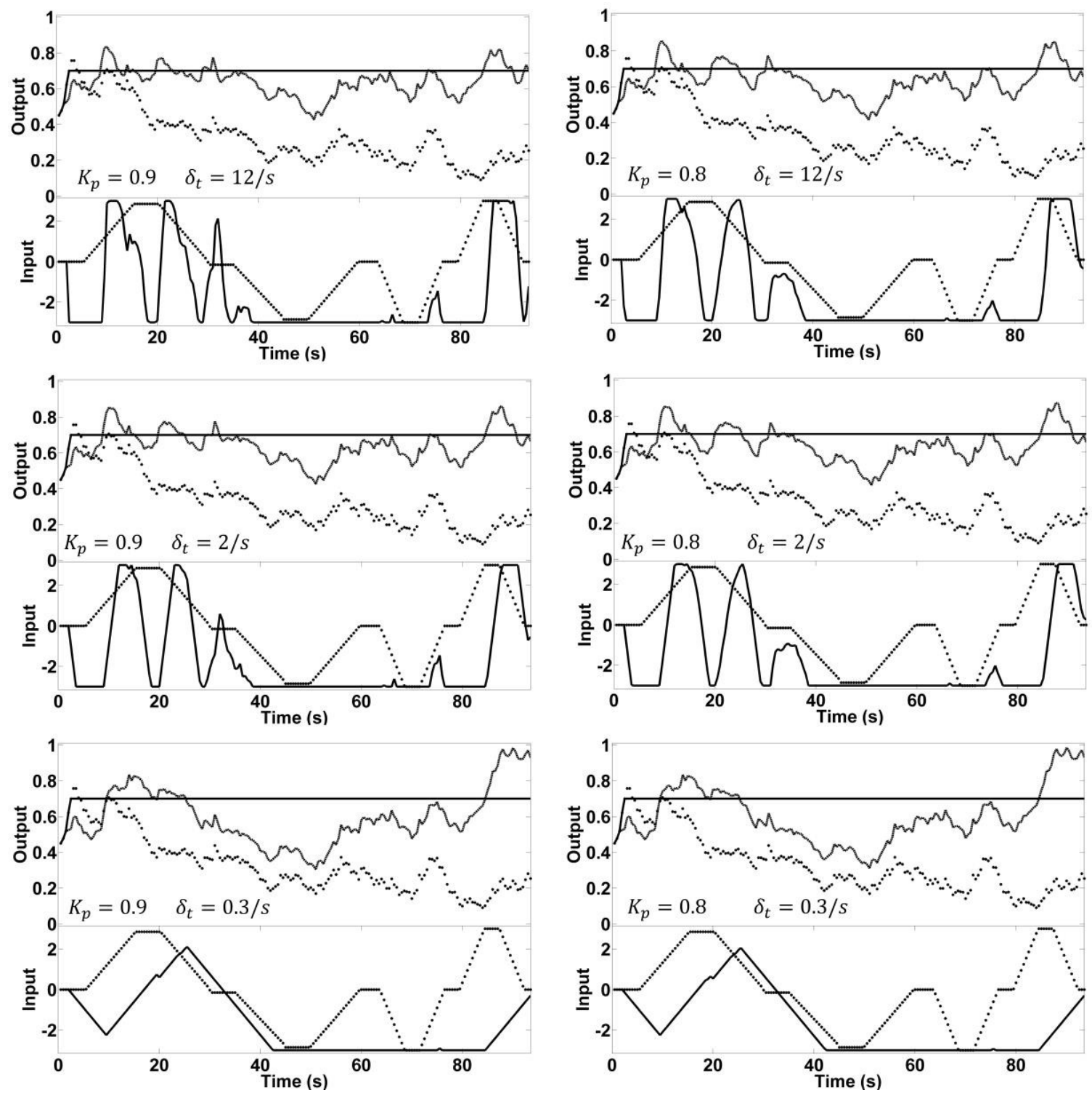


\section{Figure 12}

Examples of excitement constrained generalized minimum variance control for volunteer No. 10 (male, the second scheme). Output: solid line denotes reference signal $\mathrm{y}_{\mathrm{t}}^{*}$, dotted line - simulated output signal $\hat{y}_{\mathrm{t}}$ as response to the control signal, and dashed line - observed output yt as response to the testing input. Input: solid line denotes control signal $\mathrm{x}_{\mathrm{t}}^{*}$ and dashed lines - testing input $\mathrm{x}_{\mathrm{t}}$
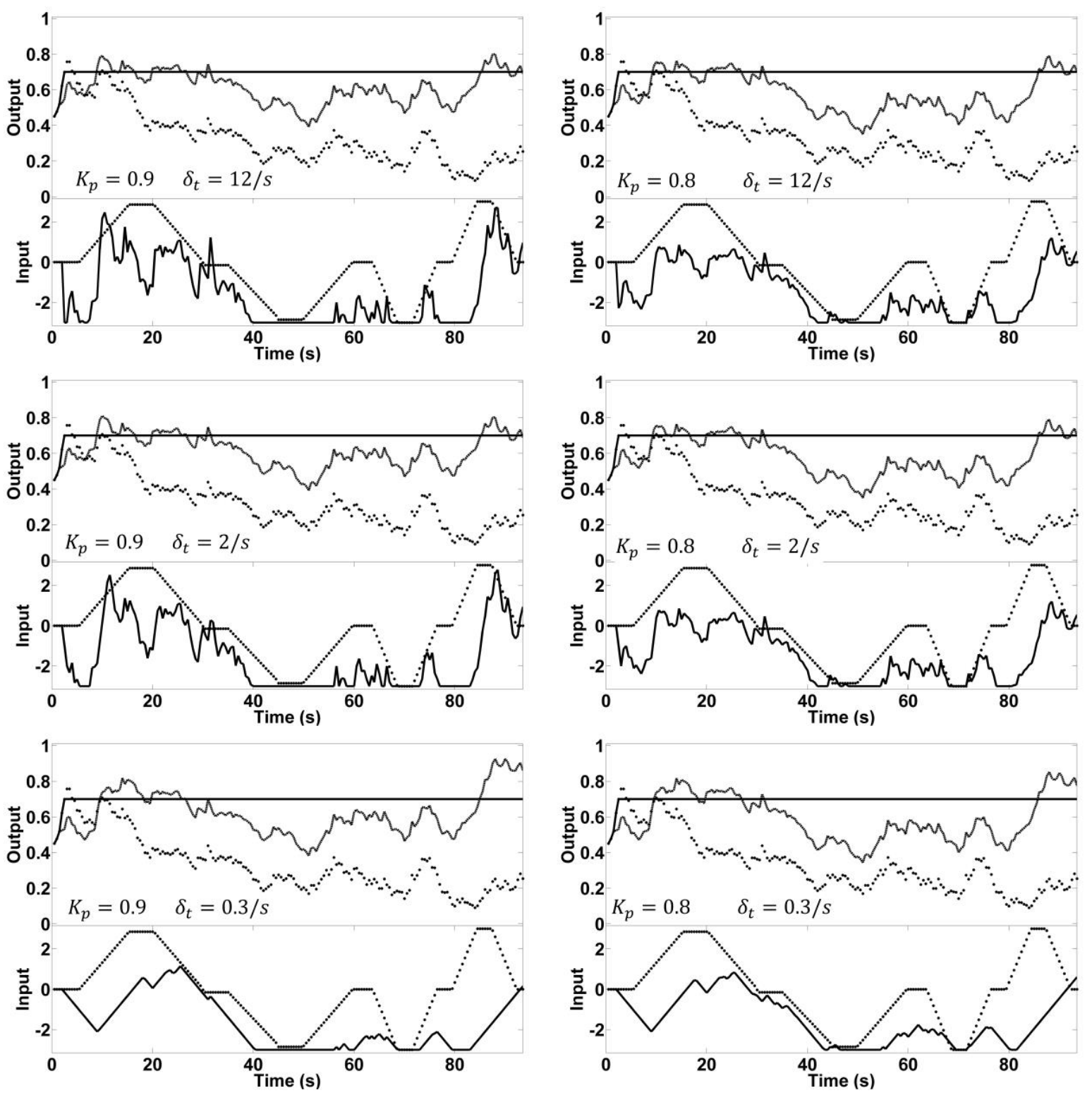
Figure 13

Examples of excitement control results with constrained minimum variance scheme for volunteer No.4 (female, left) and No. 10 (male, right). Output: solid line denotes reference signal $\mathrm{y}_{t}^{*}$, dotted line - simulated output signal $\hat{y}_{t}$ as response to the control signal, and dashed line - observed output $\mathrm{y}_{\mathrm{t}}$ as response to the testing input. Input: solid line denotes control signal $x_{t}^{*}$ and dashed lines - testing input $x_{t}$
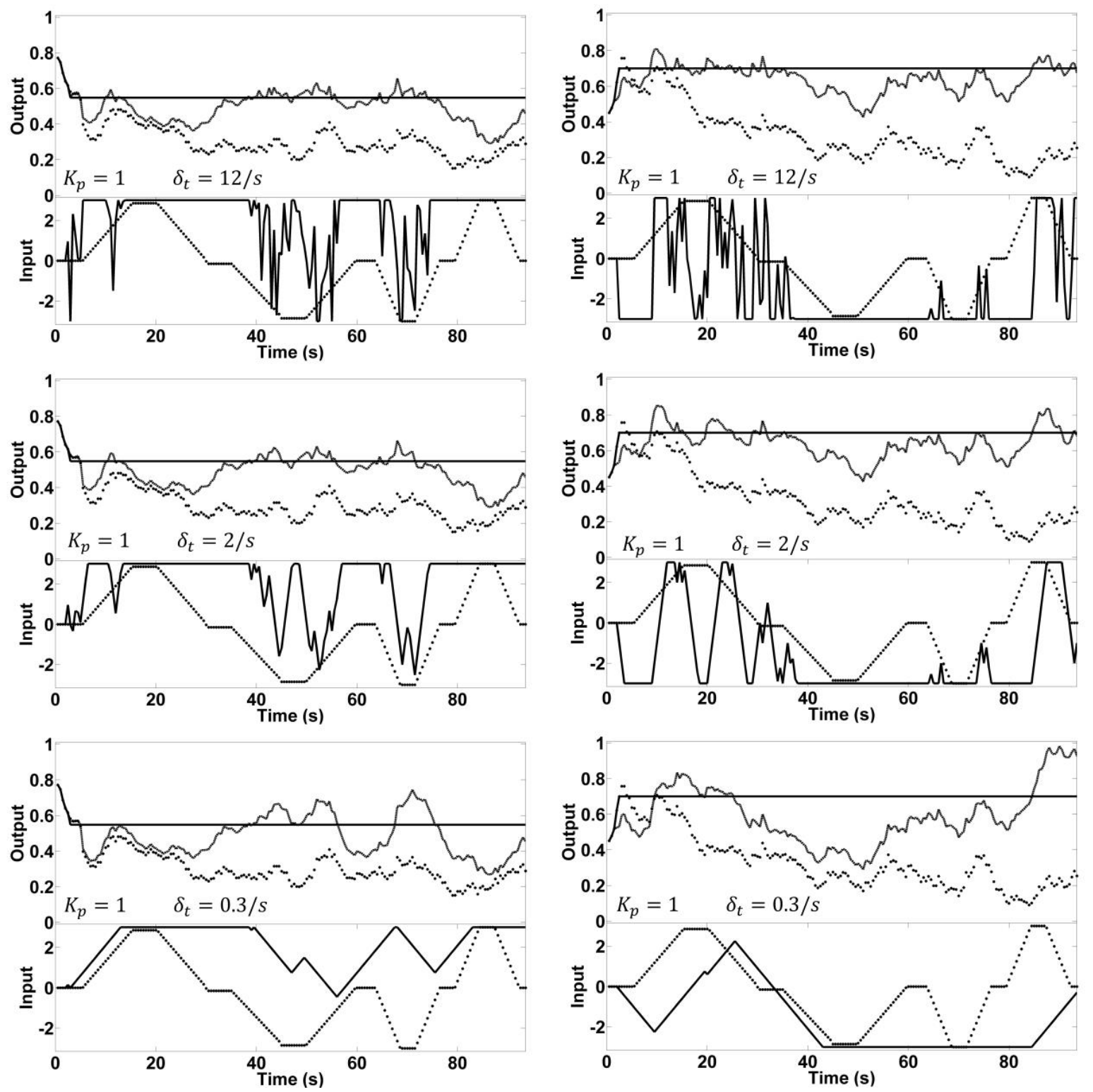
variance control criteria in an admissible domain for control signal - changing distance-between-eyes in a 3D face. Numerical calculation method of the weight factor in constrained generalized minimum variance control law (13) - (16) or the weight coefficient in control criterion (11) is proposed. This method is based on an admissible value of the systematic control error (29), which defines gain (24) of the closedloop transfer functions (25).

Analysis of the results of the experiments demonstrates sufficiently good control quality of excitement

\section{References}

1. Astrom, K. J. Introduction to Stochastic Control Theory. Academic Press, New York, 1970.

2. Astrom, K. J., Wittenmark, B. Computer Controlled Systems - Theory and Design (3rd ed 1997). Prentice Hall, Upper Saddle River, 1984.

3. Baumgartner, T., Lutz, K., Schmidt, C. F., Jancke L. The Emotional Power of Music: How Music Enhances the Feeling of Affective Pictures. Brain Research, 2006, 1075 (1), 151-164.https://doi.org/10.1016/j.brainres.2005.12.065

4. Bitmead, R. R., Gevers, M., Werts, V. Adaptive Optimal Control. The Thinking Man's GPC. Prentice Hall International, Hemel Hempstead, 1990.

5. Camacho, E. F., Bordons, C. Model Predictive Control. Springer, Berlin, 1998. https://doi.org/10.1007/978-14471-3398-8_2

6. Clarke, D. W., Mohtadi, C., Tuffs, P. S. Generalized Predictive Control: Parts I and II. Automatica, 1987, 23, 137160. https://doi.org/10.1016/0005-1098(87)90088-4

7. Clarke, D. W. Advances in Model Predictive Control. Oxford Science Publications, UK, 1994.

8. Eykhoff, P. System Identification. Wiley, New York, 1974.

9. Goodwin, G. C., Payne R. L. Dynamic System Identification: Experiment Design and Data Analysis. Academic Press, New York, 1977.

10. Harrison, T., Mitrovic, T. The Emotiv Mind: Investigating the Accuracy of the Emotiv EPOC in Identifying Emotions and Its Use in an Intelligent Tutoring System. The University of Canterbury, 2013, 1-59. signal - stabilized excitement signal level is on average $70-80 \%$ higher compared to the average of observed response as reaction to the testing input. The first scheme of the constrained generalized minimum variance control is not sensitive to the decrease of the gain (24) and is close to the scheme of constrained minimum-variance-control. Experiment results demonstrated possibility to decrease variations of the changing distance between-eyes in 3D face using a limited signal change speed and using a generalized minimum variance control with lower gain (24).

11. Hondrou, C., Caridakis, G. Affective, Natural Interaction Using EEG: Sensors, Application and Future Directions. In Artificial Intelligence: Theories and Applications. Springer, Berlin, 2012, 7297, 331-338. https:// doi.org/10.1007/978-3-642-30448-4_42

12. Isermann, R. Digital Control Systems. Springer, Berlin, 1981. https://doi.org/10.1007/978-3-662-02319-8

13. Jiang, L., Guan, C., Zhang, H., Wang, C., Jiang, B. Brain Computer Interface-Based 3D Game for Attention Training and Rehabilitation. In: Proceedings of 6th IEEE Conference on Industrial Electronics and Applications. Piscataway: IEEE, 2011, 124-127. https://doi. org/10.1109/ICIEA.2011.5975562

14. Kaminskas, V. Dynamic System Identification via Discrete-Time-Observations: Part 1 - Statistical Method Foundations. Estimation in Linear Systems. (1982) Part 2 - Estimation in Nonlinear Systems (1985). Vilnius, Mokslas, 1982, 1985.

15. Kaminskas, V. Predictor-Based Self-Tuning Control Systems. In: 33 Internationales Wissenschaftliches Kolloquium, Ilmenau, 24-28, 10.1988, Heft 1, Vortragsreiche A1, Technische Kybernetik/ Automatisierungstechnik, Ilmenau, Germany, Technishe Hochshule Ilmenau, 1988, 153-156.

16. Kaminskas, V. Predictor-Based Self-Tuning Control. Power Engineering. Vilnius, Lithuania, Academy of Science, 1997, 3, 18-22.

17. Kaminskas, V. Predictor-Based Self Tuning Control with Constraints. In: Model and Algorithms for Global Optimization. Optimization and Its Applications. Springer, Berlin, 2007, 4, 333-341. https://doi. org/10.1007/978-0-387-36721-7_20 
18. Kaminskas, V., Tallat-Kelpša, ¿̌., Šidlauskas, K. Self-Tuning Minimum Variance Control of Nonlinear Wiener-Hammerstein Type Systems. In: Identification and Parameter Estimation: Selected Papers from the 8th IFAC/IFORS Symposium, Beijing, PRC, 27-31 August 1988. Oxford, Pergamon Press, 1989, 384-389.

19. Kaminskas, V. Janickienè, D., Vitkutè, D. Self-Tuning Control of a Stochastic Nonlinear Object. In: Adaptive Systems in Control and Signal Processing: 5th IFAC Symposium, Glasgow, 19-21 April 1989. Oxford, Perganon Press, 1990, 171-175. https://doi.org/10.1016/B9780-08-035727-0.50034-2

20. Kaminskas, V., Janickienè, D., Vitkutè, D. Self-Tuning Control of the Nuclear Reactor Power. In: Automatic Control in the Service of Mankind: Proceedings of the 11th World Congress of the IFAC, Tallinn, Estonia, 1317 August 1990. Oxford, Perganon Press, 1991, 11, 91-96. https://doi.org/10.1016/S1474-6670(17)51402-0

21. Kaminskas, V., Šidlauskas, K., Tallat-Kelpša, Č. Constrained Self-Tuning Control of Stochastic Extremal Systems. Vilnius: Institute of Mathematics and Informatics, Informatica, 1991, 2(1), 33-51.

22. Kaminskas, V., Janickienè, D., Vitkutè D. Self-Tuning Constrained Control of a Power Plant. In: Control of a Power Plants and Power Systems: Selected Papers from the IFAC Symposium, Munich, Germany, 9-11 March. Oxford: Pergamon Press, 1992, 87-92. https:// doi.org/10.1016/S1474-6670(17)50434-6

23. Kaminskas, V., Janickienè, D., Šidlauskas, K., Vitkutè, D. Practical Issues in the Implementation of Predictor-Based Self-Tuning Control Systems. Vilnius: Institute of Mathematics and Informatics, Informatica, 1993, 4 (1-2), 3-20.

24. Kaminskas, V., Vaškevičius, E., Vidugirienè, A. Modeling Human Emotions as Reactions to a Dynamical Virtual 3D Face. Vilnius University, Informatica, 2014, 25 (3), 425-437. https://doi.org/10.15388/Informatica.2014.22

25. Kaminskas, V., Ščiglinskas, E., Vidugirienè, A. Predictor-Based Control of Human Emotions when Reacting to a Dynamic Virtual 3D Face Stimulus. In: Proceedings of the 12th International Conference on Informatics in Control, Automation and Robotics, France, Colmar, 2015, 1, 582-587. https://doi. org/10.5220/0005543005820587

26. Kaminskas, V., Vidugirienè, A. A Comparison of Hammerstein - Type Nonlinear Models for Identification of Human Response to Virtual 3D Face Stimuli. Vilnius University, Informatica, 2016, 27 (2), 283-297. https:// doi.org/10.15388/Informatica.2016.85
27. Kaminskas, V., Ščiglinskas, E. Minimum Variance Control of Human Emotion as Reactions to a Dynamic Virtual 3D Face. In: AIEEE 2016: Proceedings of the 4th Workshop on Advances in Information, Electronic and Electrical Engineering, Lithuania, Vilnius, 2016, 1-6. https://doi.org/10.1109/AIEEE.2016.7821810

28. Kaminskas, V., Ščiglinskas, E. Predictor-Based Control of Human Response to a Dynamic 3D Face using Virtual Reality. Vilnius University, Informatica, 2018, 29 (2), 251-264. https://doi.org/10.15388/Informatica.2018.166

29. Khushaba, R. N., Wise, Ch., Kodagoda, S., Louviere, J., Kahn, B. E., Townsend, C. Consumer Neuroscience: Assessing the Brain Response to Marketing Stimuli using Electroencephalogram (EEG) and Eye Tracking. Expert Systems with Applications, 2013, 40 (9), 38033812. https://doi.org/10.1016/j.eswa.2012.12.095

30. Lin, Y. P., Wang, C. H., Jung, T. P., Wu, T. P., Jeng, S. K., Duan, J. R., Chen, J. H. EEG-Based Emotion Recognition in Music Listening. IEEE Transactions on Biomedical Engineering, 2010, 57(7), 1798-1806. https://doi. org/10.1109/TBME.2010.2048568

31. Liu, Y., Sourina, O., Hafiyyandi, M. R. EEG-Based Emotion-Adaptive Advertising. Humaine Association Conference on Affective Computing and Intelligent Interaction (ACII), Geneva, Switzerland, 2013, 843-848. https://doi.org/10.1109/ACII.2013.158

32. Ljung, L. V. System Identification: Theory for the User (Second Edition 1999). Prentice-Hall, Inc., Upper Saddle River, N.Y., 1987.

33. Maskeliunas, R., Damasevicius, R., Martisius, I., Vasiljevas, M. Consumer-Grade EEG Devices: are they usable for control tasks? PeerJ, 2016, 4, 1-27. https://doi. org/10.7717/peerj.1746

34. Mattioli, F., Caetano. D, Cardoso. A, Lamounier. E. On the Agile Development of Virtual Reality Systems. Proceedings of the International Conference on Software Engineering Research and Practice (SERP), 2015, 10-16.

35. Mikhail, M., Allen, J. B., Coan, J., El-Ayat, K., El Kaliouby, R. Emotion Detection using Noisy EEG Data. 1st Augmented Human International Conference (AH'10), Article No. 7, Megeve, France, 2010, 1-7. https://doi. org/10.1145/1785455.1785462

36. Nie, D., Wang, X. W., Shi, L. C., B. L. Lu, B. L. EEG-Based Emotion Recognition during Watching Movies. In Proceedings of the 5th International IEEE/EMBS Conference on Neural Engineering, Cancun, Mexico, 2011, 667-670. https://doi.org/10.1109/NER.2011.5910636 
37. Peterka, V. Predictor-based Self-Tuning Control. Automatica, 1984, 20 (1), 39-50. https://doi.org/10.1016/00051098(84)90063-3

38. Poria, S., Cambria, E., Bajpai, R., Hussain, A. A Review of Affective Computing: From Unimodal Analysis to Multimodal Fusion. Information Fusion, 2017, 37, 98-125. https://doi.org/10.1016/j.inffus.2017.02.003

39. Sari, L., Nadhira, V. Development System for Emotion Detection Based on Brain Signals and Facial Images. World Academy of Science, Engineering and Technology International Journal of Psychological and Behavioral Sciences, 2009, 3(2), 13-19.

40. Soderstrom, T., Stoica, P. System Identification. Prentice Hall, Int., London, 1989.

41. Soderstrom, T. Discrete-Time Stochastic Systems: Estimation and Control. Prentice Hall International, London, 2002. https://doi.org/10.100'7/978-1-4471-0101-7

42. Soeterboek, A.R.M. Predictive Control: A Unified Approach. Prentice Hall International, London, 1992.
43. Sourina, O., Liu, Y.A Fractal-Based Algorithm of Emotion Recognition from EEG using Arousal Valence Model. In Proceedings of Biosignals, Rome, Italy, 2011, 209-214.

44. Suto, J., Oniga, S. Music Stimuli Recognition in Electroencephalogram Signal. Elektronika ir Elektrotechnika, 2018, 24(4), 68-r1. https://doi.org/10.5755/j01. eie.24.4.21482

45. Truschzinski, M., Müller, N. H. An Emotional Model for Social Robots. Conference: Conference: Proceedings of the $2014 \mathrm{ACM}$ /IEEE International Conference on $\mathrm{Hu}$ man-robot Interaction, Bielefeld, Germany, 2014, 1-2. https://doi.org/10.1145/2559636.2559837

46. Vaškevičius, E., Vidugirienè, A., Kaminskas, V. Identification of Human Response to Virtual 3D Face Stimuli. Information Technology and Control, 2014, 43 (1), 4756. https://doi.org/10.5755/j01.itc.43.1.5927

47. Yisi, L., Sourina, O., Hou, X. Neurofeedback Games to Improve Cognitive Abilities. In: International Conference on Cyberworlds (CW), IEEE, Santander, Spain, 2014, 161-168. 